\title{
Contact Effect Contribution to the High Efficiency of Lithium Chloride Against the Mite Parasite of the Honey Bee
}

\author{
Éva Kolics ${ }^{1}$, Kinga Mátyás ${ }^{1}$, János Taller ${ }^{1}$, András Specziár ${ }^{2}$ and Balázs Kolics ${ }^{1, *}$ \\ 1 Department of Plant Sciences and Biotechnology, Georgikon Faculty, University of Pannonia, \\ H-8360 Keszthely, Hungary; kolicseva@gmail.com (É.K.); petrovicsnemkk@gmail.com (K.M.); \\ taller@georgikon.hu (J.T.) \\ 2 Balaton Limnological Institute, Centre for Ecological Research, H-8237 Tihany, Hungary; \\ specziar.andras@okologia.mta.hu \\ * Correspondence: bkolics@gmail.com
}

Received: 2 April 2020; Accepted: 26 May 2020; Published: 28 May 2020

\begin{abstract}
Lithium chemicals have been proven to be very effective in eradicating Varroa destructor, the detrimental parasite of the honey bee; however, little is known about the side effects on brood and long term consequences on the colony. Earlier, it was proposed that the action mechanisms of lithium chloride do not include the contact mode. Here, we investigate this question using a paper strip test to demonstrate the concentration-dependent effectiveness of lithium in the contact mode of action, confirming that it is also a contact agent against the Varroa mite. According to our knowledge, this is the first report on the high varroicidal effect of lithium in the contact mode of action. Our findings may open up possibilities for novel ways of treatment (e.g., the use of lithiated strips) in the event that lithium salts become legal for use in apiculture.
\end{abstract}

Keywords: lithium chloride; contact mode of action; Apis mellifera; Varroa

\section{Introduction}

Maintenance of commercial honey bee (Apis mellifera) colonies is highly dependent upon the successful control of the parasitic mite Varroa destructor, recognized as the biggest threat to the western honey bee worldwide. Left untreated, mites can kill an entire colony within one or two years [1,2]; however, in areas of high bee density, it may occur within an apicultural season. Controls can be effective and of low risk of building resistance [3-6], but in some countries, they are restricted mainly to only a few chemicals, implying the potential development of acaricide resistance $[7,8]$ and reducing the possibility of mite eradication in the foreseeable future. Parallel to this, there is an increasing demand to avoid the build-up of miticide residues or their metabolites in honey and wax. Alongside novel RNAi-based approaches [9], it was observed that lithium salts may offer promising and easy-to-use chemicals for effectively treating Varroa infestation. Furthermore, treatments have been published where $100 \%$ mite mortality was found in the brood-free period with minor or no mortality of adult bees, with certain concentrations of lithium-containing chemicals $[10,11]$. Lithium chloride has been described as a varroicide that acts in a systemic mode of action in a wide range of concentrations [10]. High miticidal activity was exerted in artificial swarms applying 25 and $50 \mathrm{mM}$ lithium chloride in sugar syrup and patties, respectively [12,13].

Based on earlier unpublished attempts where lithium chloride showed high effectiveness at very low concentrations, we supposed that it might have an additional effect in a contact mode of action. The aim of this study was to test this hypothesis with insights from in situ application to enable demonstration in commercial bee colonies. 


\section{Materials and Methods}

Adult mites were freshly obtained from sealed brood cells and collected using a powder sugar test of heavily infested Apis mellifera carnica colonies. Mites were placed onto a vertical paper towel using a fine brush. To preselect vital individuals, mites that were unable to grasp strongly for about $30 \mathrm{~min}$ were discarded (6\%). The remaining mites were kept at $25^{\circ} \mathrm{C}$ for a maximum of $120 \mathrm{~min}$ in order to prevent a decrease in vitality and mobility. Subsequently, mites were placed on experimental paper strips one at a time with the help of sterile syringe needles. While transferring specimens from the paper towel, an additional pre-selection was implemented, as only mites willing to climb onto the needle by themselves were used (96\%). Experimental paperboard strips (1.5 $\mathrm{mm}$ in thickness, $3 \mathrm{~cm} \times 20 \mathrm{~cm}$ in area) were evenly impregnated with $2 \mathrm{~mL}$ lithium chloride solution $\left(\mathrm{LiCl} 1 \mathrm{H}_{2} \mathrm{O}\right)$ of one of the 11 tested concentrations ranging from $10.78 \mathrm{mM}$ to $11.04 \mathrm{M}(10.78,21.55,43.11$, and $86.22 \mathrm{mM}$, and $0.17,0.34,0.69,1.38,2.76,5.52$, and $11.04 \mathrm{M})$. The strips were fixed on a flat glass surface at a $45^{\circ}$ angle. Control strips were impregnated with deionized water from the same stock that we used for preparing the lithiated solutions. One mite was placed onto each lithiated strip and another mite onto the control strip at the same time (the number of individuals used for each exposure varied between three and 11; the total number of mites used was 71 each for the treated and control groups). After initiation, the first event recorded was the onset of tremorous movements accompanied by uncontrollable movements. The second recorded event was when the mite fell off the strip, which we considered to be the miticidal threshold. For overview of the in vitro experimental design, see Figure 1 .

The concentration-dependent contact effect of $\mathrm{LiCl}$ on the $\log 10$ transformed time of the first tremorous movement and of the drop of the mites was evaluated by analysis of variance (ANOVA) followed by Tukey HSD post hoc tests. Levene's test for the homogeneity of variance of data $\left(\mathrm{F}_{10 ; 60}=1.45, p=0.180\right.$ for time to first tremorous movement and $\mathrm{F}_{10 ; 60}=1.65, p=0.114$ for time to drop) and the Kolmogorov-Smirnov test of normality on residuals $(\mathrm{N}=71, \mathrm{D}=0.103, p=0.405$ for time to first tremorous movement and $\mathrm{N}=71, \mathrm{D}=0.109, p=0.345$ for time to drop) proved that the assumptions of the ANOVA were met. Since none of the control mites showed any tremorous movements or dropped down from the experimental paperboard during the $120 \mathrm{~min}$ of the observation period, the control groups could not be included in the ANOVA test. Therefore, the Z-test was used to compare the proportion of mites that responded (i.e., showed tremorous movement and dropped) between the control and $\mathrm{LiCl}$ treatments.

In order to demonstrate that lithiated strips show in situ effectiveness, strips were prepared by impregnating each strip with the amount used for a trickling dose for one hive (2.28 $\mathrm{mL} 5.52 \mathrm{M} \mathrm{LiCl} 1$ $\mathrm{H}_{2} \mathrm{O}=0.76 \mathrm{~g} \mathrm{LiCl} 1 \mathrm{H}_{2} \mathrm{O}$ ). This demonstration was carried out in three broodless commercial bee colonies, in the pre-wintering period in November 2019, at Keszthely, Hungary (GPS: $46^{\circ} 45^{\prime} 55.6^{\prime \prime} \mathrm{N}$, $\left.17^{\circ} 14^{\prime} 52.6^{\prime \prime} \mathrm{E}\right)$, registering the number of mites counted on the sticky board. Commercial colonies were selected according to their previous mite fall; we picked these colonies from the most infected ones of an apiary of 120 colonies, based on the mite fall carried out using Apivar strips at the end of September in the broodright stage. At that time, mite fall was 116, 102 and 67 for hives No. 1, 2 and 3, respectively. Additionally, in all of these colonies, bees with mites on the thorax could be observed in October, suggesting an elevated level of infestation. The colonies had not been treated from September until the start of the experiment in order to preserve the mites. Experimental hive No. 1, used as control, was left untreated until the end of the trial. In hives No. 2 and 3, treatment was started with one lithiated strip placed in the middle of the nest. Colonies were broodless in order to assure that the varroicide effect was not influenced by the addition of hive-born mites. After tracking the effect for five days by counting mites, five additional strips were inserted and the recording of mite fall was continued. Finally, all three hives were controlled by trickling lithiated syrup ( $40 \mathrm{~mL}, 250 \mathrm{mM}$ ) at the same time. 


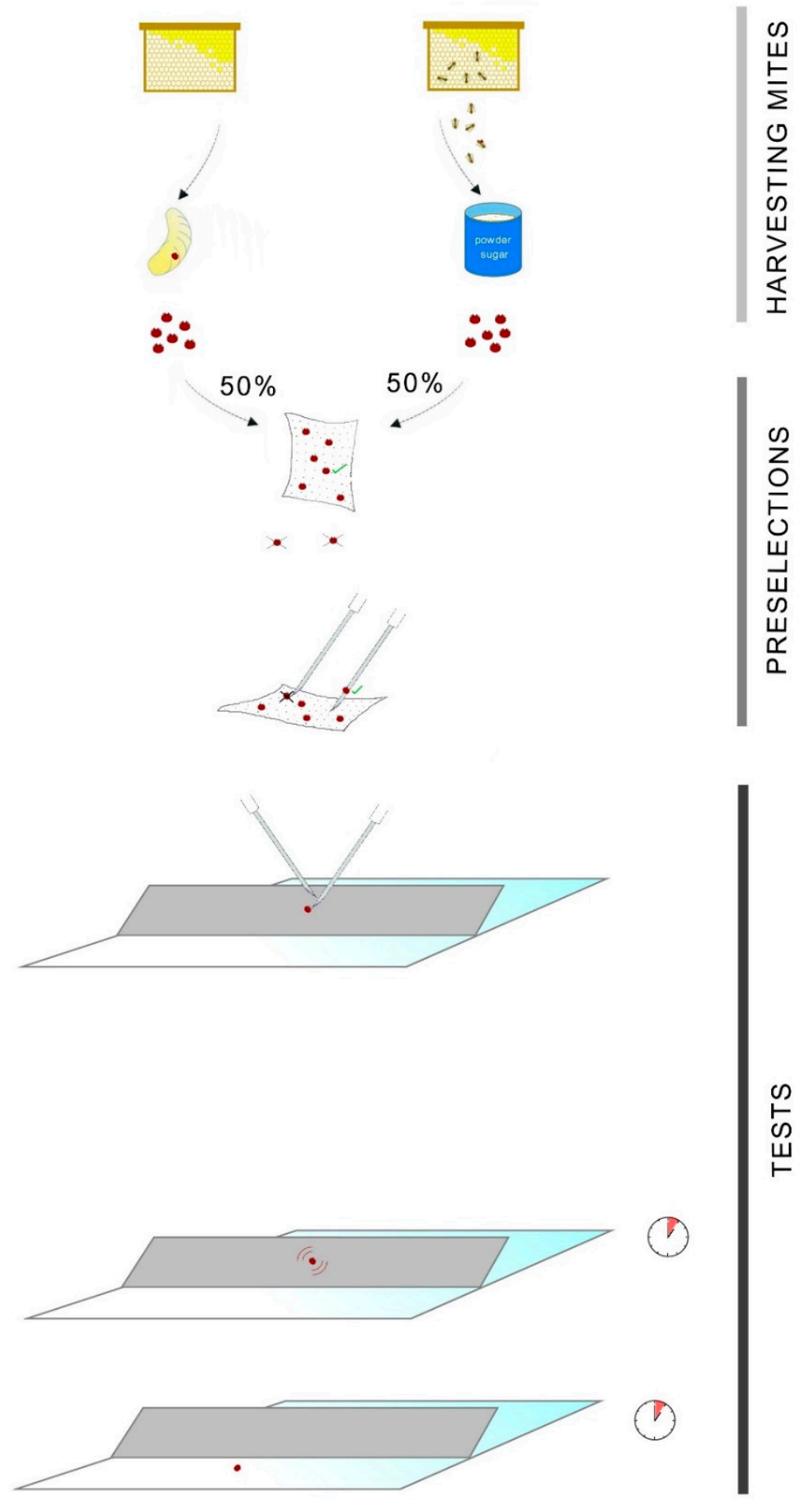

Figure 1. Overview of the experimental design. Mites collected from sealed brood cells using powder sugar were preselected to keep only vital individuals, discarding mites unable to grasp a paper towel. Subsequently, mites were placed on the experimental paper strips one at a time with the help of sterile syringe needles, using only mites willing to climb onto them. Paperboard impregnated with lithium chloride solution was fixed on a flat glass surface at a $45^{\circ}$ angle, while control strips were impregnated with deionized water. One mite was placed onto each lithiated strip and another mite onto the control strip at the same time. After initiation, the first event recorded was the onset of tremorous, uncontrolled movements. The second recorded event was when the mite fell off the strip, considered to be the miticidal threshold. 


\section{Results}

In the paper strip-based contact tests, mites on control strips either remained immobile $(n=58)$ or moved away by a maximum of $2 \mathrm{~cm}$ on the surface $(n=12)$; none of them fell down or showed similar signs to those on treated strips $(Z=11.9, p<0.001$ for both tremorous movement and drop between control and LiCl-treated groups). On the paper strips impregnated with increasing concentrations of lithium chloride, the duration of time until the first appearance of tremorous movements in the mites became progressively shorter. At the lowest concentration $(10.78 \mathrm{mM})$, symptoms appeared about after $66 \mathrm{~min}$ in average and mites fell down after $84 \mathrm{~min}$. At the highest concentration (11.04 M), mites started to show tremorous symptoms within about a minute and fell down in the third minute of the trial on average (Figure 2). It is worth noting that none of the treated mites that fell off the strip recovered from the lithium-caused symptoms at any of the lithium concentrations tested. Their tremor tended to fade gradually into uncontrollable movement and they finally ended up immobile. Every mite exposed to lithium was first affected by tremor and subsequently dropped. Only the time that passed until the onset of tremor and mite fall showed differences according to concentration.

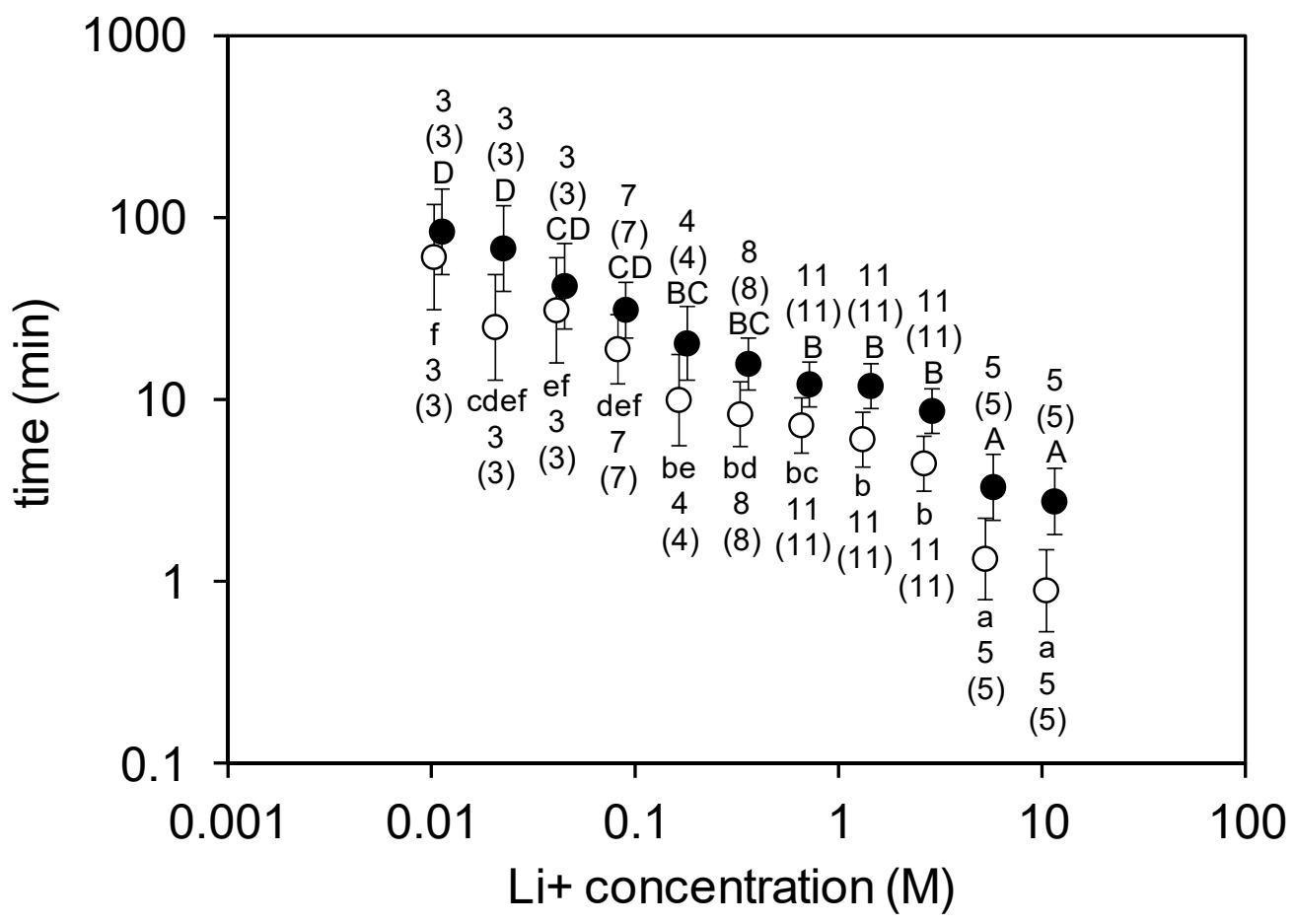

Figure 2. Analysis of variance (ANOVA) showed a concentration-dependent response of mites to lithium chloride $(\mathrm{Li}+)$ contact treatment, as monitored by time (mean $\pm 95 \% \mathrm{CI}$ ) to first tremorous movement $\left(\bigcirc ; F_{10 ; 60}=21.2, p<0.001, \log 10\right.$ transformed data $)$ and time to drop $\left(\bullet ; F_{10 ; 60}=21.2\right.$, $p<0.001, \log 10$ transformed data) from the treated paperboard strip. Plotted values not sharing any letter (lowercase for time to first tremorous movement and uppercase for time to drop) are statistically different at $p<0.05$ (Tukey HSD post hoc test). The number of mites tested in the treated and control groups and the number of mites that responded (in brackets) to the treatment are indicated. Since none of the control mites responded (neither showed tremorous movements nor dropped) during the $120 \mathrm{~min}$ of the observation period (time to first tremorous movement $>120$ and time to drop $>120$ ), the values for the control mites could not be plotted. Note that in order to improve the readability of the graph, the data on time to first tremorous movement and time to drop are shown slightly offset to the side of the actual $\mathrm{Li}+$ concentration.

In the two commercial colonies (No. 2 and 3), which were used to test whether a contact effect can be achieved in situ, 24 and 6 mite falls were detected during the first five days of the treatment carried out by placing a single lithiated strip into each hive. At the same time, in the control hive (No. 1), 
only three mite falls were registered. The number of mite falls significantly increased in the second phase, when we inserted an additional five strips into each of the two treated hives and left them for 10 days (without replacement or refreshment of the previous strip). This treatment resulted in a fall of 198 and 41 mites for hives No. 2 and 3 respectively, whereas only four mites fell in the control hive during the same period.

Finally, the application of trickling lithiated syrup at the end of the 15th day yielded additional falls of 18, 5 and 120 individuals in hives No. 2, 3, and 1 (control) after 10 days respectively. A subsequent powder sugar test carried out on $100 \mathrm{~g}$ of bees yielded no mites in any of the hives (a summary of the results can be found in Table 1). The symptoms of the freshly fallen mites under the treatment carried out with both lithiated strips and trickling were identical to those observed in the contact test. Applying a strip test to the commercial colonies confirmed that the contact mode of action may be exerted in situ at certain concentrations.

Table 1. In situ testing resulted in a high number of mites on the sticky board.

\begin{tabular}{lccc}
\hline \multicolumn{1}{c}{ Hives } & Control (No. 1) & No. 2 & No. 3 \\
\hline Mite fall after Apivar treatment 1.5 months before the trial & 116 & 102 & 67 \\
\hline One strip for 5 days (beginning of day 1) & 3 & 24 & 6 \\
Additional 5 strips inserted (end of day 5) & 4 & 198 & 41 \\
Trickling lithiated syrup (end of day 15) & 120 & 18 & 5 \\
Powdered sugar test (day 15) & 0 & 0 & 0 \\
\hline
\end{tabular}

\section{Discussion}

The first publication on the varroicidal effect of lithium salts revealed that they have high effectiveness with a systemic mode of action, exerting $100 \%$ mite mortality and low toxicity to adult bees, in artificial swarms already at a concentration of $25 \mathrm{mM}$ [10,11].

Here we present novel results proving that $\mathrm{LiCl}$ also has a strong contact effect on mites. This finding widens the range of the potential applicability of this compound as a miticide in honey bee colonies. Moreover, contact tests with impregnated paper strips revealed the irreversible effect of $\mathrm{LiCl}$ on mites even at very low concentration. It should be noted that the lithium concentration of the trickling solution may have implications for its two-level action (i.e., systemic and contact) as well.

The lowest tested concentration $(10.78 \mathrm{mM})$ of $\mathrm{LiCl}$ solution was set according to the requirement that impregnated strips should remain wet for the whole period of treatment. This criterion was set because we assume that the penetration of lithium to the parasite is effective only in solution. The lithiated strips remained wet at the highest concentration (11.04 M) for at least 15 days both in vitro and in situ, revealing that $\mathrm{LiCl}$ might not need any additional humectant for long-term contact treatment in cases where this concentration is used on strips.

The application of $\mathrm{LiCl}$ as a contact treatment may represent a beneficial alternative to feeding it to bees and can utilize its systemic mode of action in mite control. Contact treatments might imply a possible lowered risk of honey contamination [14], compared with previous approaches where lithium was administered via feeding [10,11]. Our investigations were restricted to the pre-wintering, brood-free stage of bee colonies. Although post-experiment powder sugar tests did not yield any mites, since only $100 \mathrm{~g}$ of bees were tested in each hive (according to the protocol of breeders of AGT, Germany [15]), colonies might have had remaining mites, but it is likely that they did not meet the harmful threshold. Furthermore, methodological restrictions inevitably accompany this pilot study, limiting our knowledge of the efficacy and eventual side effects of $\mathrm{LiCl}$ during the reproductive season.

\section{Conclusions}

To conclude, as well as the previously verified systemic mode of action [10], LiCl clearly has a contact effect on mites, and this feature may significantly extend the range of its applicability. The bifold mechanisms of lithium chloride in mite control may support lithium as a promising tool for controlling 
mite infection if it becomes a registered varroicide. However, further research is needed to determine the concentration and the most optimal method with regard to its efficacy, which may also depend on temperature and humidity conditions. Moreover, detailed examination is required to quantify the eventual side effects on brood.

Author Contributions: Conceptualization, É.K. and B.K.; methodology, B.K.; software, A.S.; validation, A.S; investigation, K.M., É.K. and B.K.; resources, B.K.; data curation, A.S.; writing一original draft preparation, É.K., B.K. and K.M.; writing-review and editing, B.K., É.K., K.M. and A.S.; visualization, B.K. and A.S.; funding acquisition, J.T. and B.K. All authors have read and agreed to the published version of the manuscript.

Funding: This researchwork was supported by the Hungarian Government and the European Union, with the co-funding of the European Regional Development Fund in the frame of Széchenyi 2020 Programme GINOP-2.3.2-15-2016-00054 and EFOP-3.6.3-VEKOP-16-2017-00008 projects. The APC was funded by GINOP-2.3.2-15-2016-00054 project.

Acknowledgments: We would like to thank the following Hungarian beekeepers for providing colonies for our experiment: Imre Bognár (Gelse), András and Ernő Kiss (Varászló), László Papp (Varászló), Vince Bengyák (Miháld), Ferenc Juráskovics (Nikla), József Palacki (Keszthely), Árpád Kovács (Sávoly) and László Imre, László Balogh, István Horváth, János Fürst (Nagyatád) and Ferenc Kolics (Nagyatád/Bolhó). We also thank László Orbán for his advice on writing and finalizing the manuscript.

Conflicts of Interest: The authors declare no conflict of interest. The funders had no role in the design of the study; in the collection, analyses, or interpretation of data or in the writing of the manuscript.

\section{References}

1. Spivak, M.; Reuter, G. A Sustainable Approach to Controlling Honey Bee Diseases and Varroa Mites; USDA: Washington, DC, USA, 2005; pp. 1-6.

2. Barlow, V.M.; Fell, R.D. Sampling Methods for Varroa Mites on the Domesticated Honeybee; Virginia Cooperative Extension: Virginia, VA, USA, 2006; pp. 1-3.

3. Maggi, M.D.; Damiani, N.; Ruffinengo, S.R.; Brasesco, M.C.; Szawarski, N.; Mitton, G.; Mariani, F.; Sammataro, D.; Quintana, S.; Eguaras, M.J. The Susceptibility of Varroa Destructor against Oxalic Acid: A Study Case. Bull. Insectol. 2017, 70, 39-44.

4. Milani, N. Activity of Oxalic and Citric Acids on the Mite Varroa Destructor in Laboratory Assays. Apidologie 2001, 32, 127-138. [CrossRef]

5. Nanetti, A.; Rodriguez-García, C.; Meana, A.; Martín-Hernández, R.; Higes, M. Effect of Oxalic Acid on Nosema Ceranae Infection. Res. Vet. Sci. 2015, 102, 167-172. [CrossRef] [PubMed]

6. Imdorf, A.; Bogdanov, S.; Ochoa, R.I.; Calderone, N.W. Use of Essential Oils For The Control Of Varroa Jacobsoni Oud. in honey bee colonies. Apidologie 1999, 30, 209-228. [CrossRef]

7. Mozes-Koch, R.; Slabezki, Y.; Efrat, H.; Kalev, H.; Kamer, Y.; Yakobson, B.A.; Dag, A. First Detection in Israel of Fluvalinate Resistance in the Varroa Mite Using Bioassay and Biochemical Methods. Exp. Appl. Acarol. 2000, 24, 35-43. [CrossRef] [PubMed]

8. Spreafico, M.; Eördegh, F.R.; Bernardinelli, I.; Colombo, M. First detection of strains of Varroa Destructor Resistant to Coumaphos. Results of laboratory tests and field trials. Apidologie 2001, 32, 49-55. [CrossRef]

9. Garbian, Y.; Maori, E.; Kalev, H.; Sharoni Shafir, S.; Sela, I. Bidirectional Transfer of Rnai between Honey Bee and Varroa Destructor: Varroa Gene Silencing Reduces Varroa Population. PLoS Pathog. 2012, 8, e1003035. [CrossRef] [PubMed]

10. Ziegelmann, B.; Abele, E.; Hannus, S.; Beitzinger, M.; Berg, S.; Rosenkranz, P. Lithium Chloride Effectively Kills the Honey Bee Parasite Varroa Destructor by a Systemic Mode of Action. Sci. Rep. 2018, 8, 683. [CrossRef] [PubMed]

11. Stanimirovic, Z.; Uroš, G.; Marko, R.; Nevenka, A.; Jovanovic, N.; Vejnovic, B.; Stevanovic, J. Looking for the Causes of and Solutions to the Issue of Honey Bee Colony Losses. Acta Vet. Beograd 2019, 69, 1-31. [CrossRef]

12. Kolics, B.; Sajtos, Z.; Matyas, K.; Kolics, E.; Taller, J.; Baranyai, E. Lithium Chloride—Hazard or Possibility? In Proceedings of the 46th APIMONDIA International Apicultural Congress, Montréal, QC, Canada, 8-12 September 2019. 
13. Ziegelmann, B.; Blumenschein, M.; Rein, C.; Lang, V.; Hannus, S.; Rosenkranz, P. Varroa Treatment of Brood-Free Honey Bee Colonies with Lithium Chloride. In Proceedings of the 46th APIMONDIA International Apicultural Congress, Montréal, QC, Canada, 8-12 September 2019.

14. Menkissoglu-Spiroudi, U.; Tsigouri, A.D.; Diamantidis, G.C.; Thrasyvoulou, A.T. residues in honey and beeswax caused by beekeeping treatments. Fresenius Environ. Bull. 2001, 10, 445-450.

15. Büchler, R. Methodenhandbuch Der Arbeitsgmeinschaft Toleranzzucht (AGT); Deutschen, I., Ed.; Deutschen Imkerbund: Kirchhain, Germany, 2013.

(C) 2020 by the authors. Licensee MDPI, Basel, Switzerland. This article is an open access article distributed under the terms and conditions of the Creative Commons Attribution (CC BY) license (http://creativecommons.org/licenses/by/4.0/). 